\title{
Residual tumor after the salvage surgery is the major risk factors for primary treatment failure in malignant ovarian germ cell tumors: A retrospective study of single institution
}

Chung Won Lee ${ }^{1}$, Min Jong Song ${ }^{2}$, Sung Taek Park ${ }^{3}$, Eun Young Ki ${ }^{3}$, Sung Jong Lee ${ }^{4}$, Keun Ho Lee ${ }^{4}$, Ki Sung Ryu ${ }^{1}$, Jong Sup Park ${ }^{3}$ and Soo Young Hur ${ }^{3^{*}}$

\begin{abstract}
Background: Malignant ovarian germ cell tumors are rare, and knowledge of their prognostic factors is limited, with little available randomized data. This study was conducted to evaluate the clinicopathologic characteristics of malignant ovarian germ cell tumors and to determine the association of their prognostic factors to primary treatment failure.
\end{abstract}

Methods: The medical records of 57 patients with stages I to IV malignant ovarian germ cell tumor were retrospectively reviewed, and their clinicopathologic and treatment-related data were collected and analyzed.

Results: The median age at the diagnosis was 23.3 years (range: 8-65 years), and the median follow-up period was 108 months (range: 48-205 months). The histological types of the tumors were immature teratoma $(n=24)$, dysgerminoma $(n=20)$, endodermal sinus tumor $(n=8)$, mixed germ cell tumor $(n=4)$, and choriocarcinoma ( $n$ $=1$ ). $66.7 \%$ of the patients had stage I disease; $5.2 \%$, stage II; $26.3 \%$, stage III; and $1.8 \%$, stage IV. After the initial surgery, 49 patients (86\%) received cisplatin-based chemotherapy. The five-year survival rate was $96.5 \%$. There were six primary treatment failures, with two of the patients dying of the disease, and the median time to the recurrence was 8 months. The histological diagnosis $(P<0.0001)$, tumor stage $(P=0.0052)$, elevation of beta-hCG $(P=0.0134)$, operation methods $(P=0.0006)$, and residual tumor after the salvage surgery $(P<0.0001)$ were significantly associated with the risk of primary treatment failure in the univariate analysis. In the multivariate analysis, the residual tumor after the salvage surgery was the only significant variable associated with primary treatment failure $(P=0.0011$, Hazard ratio $=29.046$, 95\% Confidence interval 3.832-220.181).

Conclusion: Most malignant ovarian germ cell tumors have excellent prognoses with primary treatment, and good reproductive outcomes can be expected. Because primary treatment failure is associated with the residual disease after the salvage surgery, knowledge of the presence or absence of this risk factor may be helpful in risk stratification and individualization of adjuvant therapy in malignant ovarian germ cell tumors. Further large-scale prospective studies to confirm these results should be performed.

Keywords: Malignant ovarian germ cell tumor, Primary treatment failure, Prognostic factors

\footnotetext{
* Correspondence: hursy@catholic.ac.kr

${ }^{3}$ Department of Obstetrics and Gynecology, Seoul St. Mary's Hospital, School of Medicine, the Catholic University, 505, Banpo-dong, Seocho-gu, Seoul,

137-040, Korea

Full list of author information is available at the end of the article
} 


\section{Background}

Malignant ovarian germ cell tumors (MOGCTs) are a heterogeneous group of tumors that have several histologically different types derived from primordial germ cells of the embryonic gonad [1]. In contrast to epithelial ovarian cancer (EOC), these tumors are rare cancers, accounting for less than $5 \%$ of all ovarian malignancies, and typically occur primarily in girls and young women [2]. In addition, $50-75 \%$ of MOGCTs are stage I at their diagnosis; and even in the advanced stage of the disease, the survival rates are $60-80 \%$ [2-4]. In the past, radical surgery was performed due to the presumed risk of microscopic involvement of the grossly normal contralateral ovary and uterus; but recent multimodality therapy with initial fertility-sparing surgery and platinumbased chemotherapy has improved the prognosis significantly, even in patients with advanced diseases.

Because of the rare incidence of these tumors, however, experience with MOGCTs is limited, with little available randomized data and information on their management in a sufficient number of patients [1,4-5]. There is no doubt that early-stage MOGCT patients have excellent prognoses with standard treatment, whereas advanced and recurrent tumors remain a challenge. In addition, the fact that most MOGCTs occur in reproductive-age women is of great importance to the treatment of the disease. Prognostic factors are very important because they may influence the decision to perform less radical surgery in the early stages of the disease without compromising fertility and may be helpful in creating risk stratification models for individualization of adjuvant therapies $[4,6]$. This study reports the experience of an institution in the management of MOGCTs over a period of about 20 years. The aim of this study was to evaluate the clinicopathologic characteristics of MOGCTs and to determine the association of their prognostic factors to their primary treatment failure.

\section{Methods}

After obtaining approval from the Institutional Review Board (IRB), all women diagnosed with histologically proven MOGCTs were identified using our institutional medical database. Patients who were primarily treated elsewhere and were referred to the authors' institution for adjuvant chemotherapy or salvage therapy after the recurrence of their disease were excluded. The medical records of the patients were retrospectively reviewed, and data were collected regarding their demographics, disease characteristics, management patterns, disease recurrence, and survival.

The histological types of the disease were classified according to the World Health Organization (WHO) System [7], and the stages were assigned as described by the International Federation of Gynecology and
Obstetrics (FIGO). All the patients underwent maximal cytoreductive surgery as their primary treatment, and depending on their pathologic results and operative findings, some received adjuvant chemotherapy according to institutional guidelines. The initial surgery was considered a staging operation when peritoneal cytology, multiple biopsies, infracolic omentectomy, and lymphadenectomy were also performed. A fertility-sparing surgery was defined as preservation of the uterus and at least part of one ovary to preserve fertility. The duration of the follow-up was calculated from the pathologic diagnosis to the date of the last visit. The time to recurrence was defined as the period from the last date of primary treatment (the date of surgery or the date of adjuvant chemotherapy) to the first observation of disease progression. The recurrence/progression free survival and the time to recurrence were estimated using the method of Kaplan and Meier, and the log rank test with SPSS (Version 12.0; SPSS, Inc., Chicago, Ill) was used to assess the statistical significance of the prognostic factors. Multivariate analysis was performed using Cox's regression analysis. $\mathrm{P}$ values that were less than 0.05 were considered statistically significant. All the P values were two-sided.

\section{Results}

\section{Clinicopathologic characteristics and treatment methods}

Seventy-two women who were treated in the Division of Gynecologic Oncology at Seoul St. Mary's Hospital between January 1990 and July 2009 were identified as having had MOGCT. Among them, 57 patients received primary treatment in the authors' institution, and the remaining 15 patients were primarily treated elsewhere and were referred to the authors' institution for adjuvant chemotherapy $(\mathrm{n}=8)$ or salvage therapy after the recurrence of their disease $(n=7)$. The clinicopathologic characteristics and treatment methods of 57 patients are summarized in Tables 1 and 2 . The median age at the diagnosis was 23.3 years (range: $8-65$ years), and the median follow-up period of the survivors was 108 months (range: 48-205 months). Most of the patients were nulliparous $(n=45,78.9 \%)$. The tumor size ranged from 4 to $25 \mathrm{~cm}$ in the maximal diameter, and the mean tumor diameter was $15.2 \mathrm{~cm}$. The histological types of the tumors were immature teratoma $(n=24)$, dysgerminoma $(\mathrm{n}=20)$, endodermal sinus tumor (EST) $(\mathrm{n}=8)$, mixed germ cell tumor $(\mathrm{n}=4)$, and choriocarcinoma $(\mathrm{n}=1)$. Most of the tumors were unilateral $(\mathrm{n}=$ $51,89.4 \%$ ), but the histological types of bilateral tumors were dysgerminoma $(3 / 6,50 \%)$, EST $(2 / 6,33.3 \%)$, and mixed germ cell tumor (1/6, 16.7\%). $66.7 \%$ of the patients had stage I disease; $5.2 \%$, stage II; $26.3 \%$, stage III; and $1.8 \%$, stage IV. The alpha-fetoprotein (AFP) levels were known for 46 patients, and two patients with 
Table 1 The clinicopathologic factors associated with recurrence/progression in MOGCTs

\begin{tabular}{|c|c|c|c|}
\hline Variables & $\begin{array}{l}\text { No. Patients } \\
\text { (\%) }\end{array}$ & $\begin{array}{c}\text { Recurrence } \\
\text { No } \\
\text { (Rate, \%) }\end{array}$ & $P$ value \\
\hline \multicolumn{4}{|l|}{ Age, years } \\
\hline$<20$ & $26(45.6)$ & $2(3.5)$ & 0.1177 \\
\hline $20-40$ & $28(49.1)$ & $3(5.3)$ & \\
\hline$>40$ & $3(5.3)$ & $1(1.8)$ & \\
\hline \multicolumn{4}{|l|}{ Histological diagnosis } \\
\hline Dysgerminoma & $20(35.1)$ & $0(0.0)$ & $<0.0001$ \\
\hline Immature teratoma & $24(42.1)$ & $1(1.8)$ & \\
\hline $\begin{array}{l}\text { Endodermal sinus } \\
\text { tumor }\end{array}$ & $8(14.0)$ & $2(3.5)$ & \\
\hline Choriocarcinoma & $4(7.0)$ & $2(3.5)$ & \\
\hline $\begin{array}{l}\text { Mixed germ cell } \\
\text { tumor }\end{array}$ & $1(1.8)$ & $1(1.8)$ & \\
\hline \multicolumn{4}{|l|}{ Histological diagnosis ${ }^{\mathrm{a}}$} \\
\hline Dysgerminoma & $20(35.1)$ & $0(0.00)$ & 0.0716 \\
\hline Non-dysgerminoma & $37(64.9)$ & $6(10.5)$ & \\
\hline \multicolumn{4}{|l|}{ Stage } \\
\hline । & $38(66.7)$ & $1(1.8)$ & $0.0052^{b}$ \\
\hline$\|$ & $3(5.2)$ & $0(0.0)$ & \\
\hline III & $15(26.3)$ & $4(7.0)$ & \\
\hline IV & $1(1.8)$ & $1(1.8)$ & \\
\hline \multicolumn{4}{|l|}{ Volume of ascites, cc } \\
\hline$<100$ & $33(57.9)$ & $2(3.5)$ & 0.1277 \\
\hline$\geq 100$ & $24(42.1)$ & $4(7.0)$ & \\
\hline \multicolumn{4}{|l|}{$\begin{array}{l}\text { Elevated AFP, } \mathrm{ng} / \mathrm{ml} \\
(\mathrm{n}=46)\end{array}$} \\
\hline$<100$ & $36(78.3)$ & $4(8.7)$ & 0.4089 \\
\hline$\geq 100$ & $10(21.7)$ & $2(4.4)$ & \\
\hline \multicolumn{4}{|l|}{ Beta-hCG $(n=53)$} \\
\hline Normal & $45(84.9)$ & $3(5.7)$ & 0.0134 \\
\hline Elevated & $8(15.1)$ & $3(5.7)$ & \\
\hline
\end{tabular}

AFP, alpha-fetoprotein; hCG, human gonadotrophic hormone.

a Comparison between two groups.

${ }^{b}$ Comparison between stage I-II and stage III-IV.

immature teratoma and five with EST had elevated AFP levels that were higher than $100 \mathrm{ng} / \mathrm{ml}$. Three patients with mixed germ cell tumor who had elements of EST also had elevated AFP levels. The beta-human gonadotrophic hormone (hCG) was checked in 53 patients, and was elevated in four patients with dysgerminoma, in three with mixed germ cell tumor, and in one with choriocarcinoma.

Regarding the surgery for the primary tumor, a fertility-sparing surgery was performed in 42 patients (73.7\%), a staging operation in 31 patients (54.4\%). Lymph node involvement was reported in 10 of the 31 patients who underwent the staging operation. Most of the patients who underwent surgery had no residual disease $(n=47,82.5 \%)$; but based on the pathologic results and operative findings, stage I dysgerminoma or stage Ia, grade 1 immature teratoma was observed without postoperative adjuvant chemotherapy, and the patients who had the other pathologic results and operative findings were allowed to postoperative adjuvant chemotherapy. Forty nine patients underwent postoperative cisplatin-based chemotherapy, and the most common regimen was etoposide and cisplatin (EP), followed by bleomycin, etoposide, and cisplatin (BEP) (Table 2). Eight of the patients had pelvic or abdominal residual disease with a tumor diameter of less than $1 \mathrm{~cm}$; one patient had a $2 \mathrm{~cm}$ metastasis on his liver surface; and the patient who was diagnosed with choriocarcinoma had unresectable lung metastasis.

\section{Prognostic factors associated with primary treatment failure}

After a median follow-up of 108 months (range: 48-205 months), there were six primary treatment failures, with two patients dying of the disease, and the five-year survival rate was $96.5 \%$. Recurrence was observed in five patients $(8.8 \%)$, and disease progression was observed in one patient $(1.8 \%)$. The time to recurrence ranged from 4 to 12 months, and the median time to recurrence was 8 months. The detailed clinical features and outcomes of the patients who experienced primary treatment failure are summarized in Table 3.

The histological diagnosis $(P<0.0001)$, tumor stage $(P$ $=0.0052)$, elevation of beta-hCG $(P=0.0134)$, operation methods $(P=0.0006)$, and residual tumor after the salvage surgery $(P<0.0001)$ were significantly associated with the risk of primary treatment failure in the univariate analysis (Tables 1 and 2). The recurrence/progression-free survival rate was $100 \%$ for dysgerminoma (20/ 20), $95.8 \%$ for immature teratoma $(23 / 24), 75.0 \%$ for EST $(2 / 8), 50.0 \%$ for mixed germ cell tumor $(2 / 4)$, and $0 \%$ for choriocarcinoma $(P<0.0001)$. The rate of primary treatment failure was $1.8 \%$ for women in stages I and II, and $8.8 \%$ for women in stages III and IV $(P=$ 0.0052). Complete tumor resection was performed on 47 patients and showed a lower recurrence rate than incomplete resection $(P<0.0001)$. The age, volume of ascites, elevation of AFP, treatment modalities, and chemotherapy regimen did not affect the primary treatment failure. In the multivariate analysis, the residual tumor after the salvage surgery was the only significant variable associated with the primary treatment failure with respect to the MOGCTs $(P=0.0011$, Hazard ratio [HR] $=29.046,95 \%$ Confidence interval $[\mathrm{CI}] 3.832-220.181$ ). The Kaplan-Meier estimate of the recurrence/progression free survival based on the residual tumor after the salvage surgery (no residual mass $v s . \leq 1 \mathrm{~cm}$ of residual mass $v s .>1 \mathrm{~cm}$ of residual mass) is shown in Figure 1. The one-year recurrence/progression-free survival rate 
Table 2 Analyses of treatment-related variables associated with recurrence/progression in MOGCTs

\begin{tabular}{lcc}
\hline Variables & No. Patients (\%) & $\begin{array}{c}\text { Recurrence No } \\
\text { (Rate, \%) }\end{array}$ \\
\hline Treatment modalities & & $1(1.8)$ \\
$\quad$ Surgery only & $8(14.0)$ & $5(8.8)$ \\
$\quad$ Surgery + chemotherapy & $49(86.0)$ & \\
Operation methods & & $1(1.8)$ \\
$\quad$ Fertility sparing & $42(73.7)$ & $0(0.0)$ \\
$\quad$ Cystectomy without staging op. & $1(1.8)$ & $0(0.0)$ \\
$\quad$ USO without staging op. & $20(35.1)$ & $1(1.8)$ \\
$\quad$ USO with staging op. & $21(36.8)$ & $5(8.8)$ \\
Non-fertility sparing & $15(26.3)$ & $0(0.0)$ \\
$\quad$ Hysterectomy + BSO without staging op. & $5(8.8)$ & $5(8.8)$ \\
$\quad$ Hysterectomy + BSO with staging op. & $10(17.5)$ & 0.4342 \\
Chemotherapy regimens (n = 49) & & $1(2.0)$ \\
BEP & $9(18.4)$ & $3(6.1)$ \\
EP & $28(57.1)$ & $0(0.0)$ \\
VBP & $2(4.1)$ & $10(20.4)$ \\
Others & $10(20.4)$ & \\
Residual lesions & & $1(1.8)$ \\
None & $47(82.5)$ & $3(5.3)$ \\
$\leq 1$ cm & $8(14.0)$ & $2(3.5)$ \\
$>1$ cm & $2(3.5)$ & 0.9008 \\
\hline
\end{tabular}

USO, unilateral salpingo-oophorectomy; BSO, bilateral salpingo-oophorectomy; BEP, bleomycin, etoposide, and cisplatin; EP, etoposide and cisplatin; VBP, vinblastine, bleomycin, and cisplatin.

of the patients with no residual tumor after the salvage surgery was $97.8 \%$, and only $62.5 \%$ for the patients with $\leq 1 \mathrm{~cm}$ of residual mass, and $0 \%$ for the patients with > $1 \mathrm{~cm}$ of residual mass.

During the follow-up period, 14 patients reported attempting to conceive post-treatment, and seven patients had 10 successful pregnancies with 10 full-term live births. All these seven women had received adjuvant EP or BEP chemotherapy. There is no evidence of birth defects or other disabilities in any of the offspring. One patient diagnosed to stage IIIc EST and received 4 cycles of EP chemotherapy had acute myeloid leukemia (AML)

Table 3 Summary of clinicopathologic features, treatment, and outcome of those who failed primary treatment

\begin{tabular}{|c|c|c|c|c|c|c|c|c|}
\hline $\begin{array}{l}\text { Pt's } \\
\text { ID }\end{array}$ & Age & Histology/Stage & Primary treatment & Outcome of primary treatment & $\begin{array}{l}\text { Time to } \\
\text { relapse } \\
\text { (months) }\end{array}$ & $\begin{array}{c}\text { Site of } \\
\text { Relapse/ } \\
\text { progression }\end{array}$ & Salvage treatment & Outcome \\
\hline 1 & 18 & $\begin{array}{c}\text { Choriocarcinoma/ } \\
\text { Stage IV }\end{array}$ & $\begin{array}{l}\text { TAH + BSO } \\
+ \text { staging op } \\
+ \text { BEP chemo. }\end{array}$ & $C R$ & 4 & Brain & $\begin{array}{l}\text { EMA-CO } \\
\text { chemo. }\end{array}$ & DOD \\
\hline 2 & 25 & $\begin{array}{c}\text { Immature teratoma/ } \\
\text { Stage Ic }\end{array}$ & $\begin{array}{c}\text { USO } \\
+ \text { staging op }\end{array}$ & $C R$ & 11 & PAN & BEP chemo & $\begin{array}{c}\text { NED } \\
\text { at age } 33\end{array}$ \\
\hline 3 & 22 & $\begin{array}{l}\text { Mixed germ cell } \\
\text { tumor/Stage Illa }\end{array}$ & $\begin{array}{l}\text { TAH + BSO } \\
+ \text { staging op } \\
+ \text { EP chemo }\end{array}$ & $C R$ & 12 & Mesentery & EP chemo & $\begin{array}{c}\text { NED } \\
\text { at age } 33\end{array}$ \\
\hline 4 & 19 & EST/Stage IIla & $\begin{array}{l}\text { TAH + BSO } \\
+ \text { staging op } \\
+ \text { CP chemo. }\end{array}$ & $C R$ & 7 & Mesentery & EP chemo. & $\begin{array}{c}\text { NED } \\
\text { at age } 29\end{array}$ \\
\hline 5 & 29 & EST/Stage IIIC & $\begin{array}{l}\text { TAH + BSO } \\
+ \text { staging op } \\
+ \text { EP chemo. }\end{array}$ & $C R$ & 6 & $\begin{array}{l}\text { Pelvic lymph } \\
\text { node }\end{array}$ & VBP chemo. & $\begin{array}{c}\text { NED } \\
\text { at age } 36\end{array}$ \\
\hline 6 & 65 & $\begin{array}{l}\text { Mixed germ cell } \\
\text { tumor/Stage IIlc }\end{array}$ & $\begin{array}{l}\text { TAH + BSO } \\
+ \text { staging op } \\
+ \text { EP chemo }\end{array}$ & Progressi-on & & Liver & $\begin{array}{c}\text { Cisplatin + Paclitaxel } \\
\text { chemo. }\end{array}$ & DOD \\
\hline
\end{tabular}

$\mathrm{TAH}$, total abdominal hysterectomy; BSO, bilateral salpingo-oophorectomy; USO, unilateral salpingo-oophorectomy; EMA-CO, etoposide, methotraxate, actinomycin-D, vincristine, and cyclophosphamide; BEP, bleomycin, etoposide, and cisplatin; EP, etoposide and cisplatin; CP, cisplatin and cyclophophamide; VBP, vinblastine, bleomycin, and cisplatin; CR, complete remission; PAN, paraaortic lymph node; DOD, died of disease; NED, no evidence of disease. 


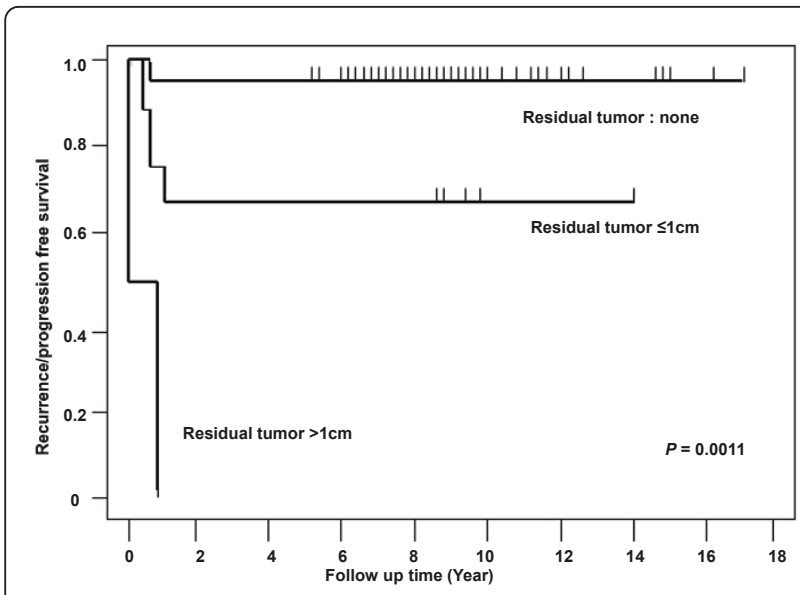

Figure 1 The recurrence/progression free survival based on the residual tumor after the salvage surgery. Figure 1 presents the Kaplan-Meier estimate of the recurrence/progression free survival based on the residual tumor after the salvage surgery (no residual mass vs. $\leq 1 \mathrm{~cm}$ of residual mass vs. $>1 \mathrm{~cm}$ of residual mass). The one-year recurrence/progression-free survival rate of the patients with no residual tumor after their salvage surgery was $97.8 \%$, and only $62.5 \%$ for the patients with $\leq 1 \mathrm{~cm}$ of residual mass, and $0 \%$ for the patients with $>1 \mathrm{~cm}$ of residual mass.

19 months after starting EP chemotherapy with 5-day etoposide $\left(100 \mathrm{mg} / \mathrm{m}^{2}\right.$ on days $\left.1-5\right)$, cisplatin (100 mg/ $\mathrm{m}^{2}$ on days 1 ), and a cumulative dose of etoposide was $3200 \mathrm{mg} / \mathrm{m}^{2}$, but the patient received allogenic bone marrow transplantation, and has no evidence of disease at present.

\section{Discussion}

The introduction of adjuvant platinum-based chemotherapy in cytoreductive surgery has improved the prognosis of MOGCTs, and the overall disease-free survival rate is more than $95 \%$ [8]. The occurrence of most MOGCTs in reproductive-age women requires special consideration, however, as it means most MOGCT patients must be treated with a fertility-sparing modality that does not compromise survival.

To accomplish this therapeutic intent, the most important thing to do is risk stratification of the diseases according to their prognosis. With their limited number of cases, however, virtually no randomized controlled trials have been conducted on MOGCTs, and several different, inconsistent prognostic factors have been reported in retrospective studies. A study by Lai et al. analyzed the prognostic factors of 93 MOGCTs, and the authors suggested that the histology (dysgerminoma vs. non-dysgerminoma, $P<0.0001$ ) and the FIGO stage (I-II vs. III-IV, $P=0.001$ ) were significantly associated with treatment failure, whereas the histology (dysgerminoma vs. nondysgerminoma, $P<0.0004)$, the residual tumor after the salvage surgery $(\geq 1 \mathrm{~cm} v s .<1 \mathrm{~cm}, P=0.0014)$, and the salvage high-dose chemotherapy failure $(P=0.0405)$ significantly influenced the overall survival [9]. In a more recent study, Lee et al. reported that the age $(\leq 40$ years $v s$. $>40$ years, $P=0.031$ ) and the FIGO stage (I-II $v s$. IIIIV, $P=0.032)$ significantly predicted recurrence in 196 Korean women with MOGCTs [4]. In the study of Murugaesu et al., univariate and multivariate analyses of 113 MOGCTs demonstrated the importance of tumor markers (AFP and beta-hCG) (relative risk [RR], 3.90; $P=$ $0.009)$ and the initial stage of the disease (RR, 5.96; $P=$ 0.03 ) as predictors of overall survival, whereas the age at the diagnosis had no prognostic value [10]. In still another study, Kumar et al. suggested lymph node involvement as an independent predictor of poor survival, with a hazards ratio of 2.87 (95\% CI 1.439-5.725; $P<$ 0.05 ) [6]. Several studies on non-dysgerminomatous ovarian germ cell tumors (NDOGCTs) have also been reported [11-14]. In these studies, an early stage [11-13], minimal residual tumor after the initial surgery [11-13], less than $100 \mathrm{cc}$ of ascites [11,12], platinum-based chemotherapy [11,12], an AFP level less than 1,000 kU/L, and a non-EST histology were found to be significantly related to a more favorable prognosis [14]. In conclusion, taking into account the results from largest series reported on MOGCTs, stage, residual disease, histological type, elevation of tumor markers, and chemotherapeutic regimen seem to be recognized as prognostic factors for patients with MOGCT. In this study, the histological diagnosis $(P<0.0001)$, tumor stage $(P<0.0001)$, elevation of beta-hCG $(P=0.0134)$, operation methods $(P=0.0006)$, and residual tumor after the salvage surgery $(P<0.0001)$ were found to be significantly associated with the risk of primary treatment failure in the univariate analysis. In the multivariate analysis, however, the residual tumor after the salvage surgery was the only significant variable associated with primary treatment failure for MOGCTs $(P=0.0011, \mathrm{HR}=29.046,95 \% \mathrm{CI}$ 3.832-220.181), whereas the correlation of the other factors could not be proven (data not shown). Significant Pvalue with a very wide confidence interval of this factor may have been caused by the fact that the majority of MOGCTs are so early staged that maximal cytoreductive surgery can be performed in most cases. In other words, it may have been caused by relatively small size of the group with residual lesions due to the excellent surgical outcome of the MOGCTs. Type of operation (fertility sparing $v s$. non-fertility sparing operation) was found to be significantly associated with the risk of primary treatment failure in the univariate analysis $(P=0.0006)$, but not in the multivariate analysis $(P=0.1493)$. The major reasons to perform a non-fertility sparing operation instead of a fertility sparing operation in this study are the willingness of patients to preserve fertility and the extent of disease. Because the authors have the 
conviction that stage III-IV or unresectable MOGCTs are expected to have poor prognostic outcome according to the authors' clinical experiences, more radical operations may be performed in this group. Therefore, patients who had non-fertility sparing operations seemed to have poor prognosis in the univariate analysis, but type of operation was not actually significant in the statistics.

The principles of cytoreductive surgery in epithelial ovarian cancer, i.e., resection of as much gross tumor as possible, have been applied to the management of MOGCTs. Two Gynecologic Oncology Group (GOG) studies indicated that patients with unresectable or incompletely resected MOGCTs had fewer chances of full remission after chemotherapy than patients with minimal residual disease $[15,16]$. Both studies had limited sample sizes, however, and the chemotherapy regimens that they employed (VAC, vincristine, actinomycin $\mathrm{D}$, and cycolphosphamide; and PVB, cisplatin, vinblastine, and bleomycin, respectively) are not the most active regimens at present [8]. The role and extent of cytoreductive surgery remain controversial despite its routine use, unless the randomized data can prove the therapeutic advantages. Nevertheless, taking into account the results of many series $[9,11-13,15,16]$ and the chemotherapy-sensitive nature of the disease, an adequate attempt at maximal cytoreduction without compromising future fertility seems a reasonable surgical approach at present. Many studies have shown that fertility-sparing surgery is a safe, reasonable treatment option that does not compromise survival, but support for such an approach shall arise not from prospective randomized trials but from experiential evidence. Gershenson et al., and Kurman et al. did not observe worsening of the prognosis associated with unilateral salpingo-oophorectomy (USO) in MOGCT patients, compared to BSO [2,17]. Tewari et al. reported that the prognoses of 46 patients with MOGCTs who underwent USO and postoperative systemic chemotherapy were excellent (five-year survival rate, 93\%) [18]. In this study, of the 42 patients with MOGCTs who underwent fertility-sparing surgery, only one grade I immature teratoma patient who did not undergo postoperative adjuvant chemotherapy had a recurrence in her para-aortic lymph node, and was successfully salvaged with BEP chemotherapy.

The introduction of multimodality therapy with initial surgery and subsequent chemotherapy has dramatically improved the prognosis of patients with MOGCTs. The evolution of systemic therapy of MOGCTs has paralleled the advances made in the treatment of testicular germ cell tumors [1]. Lessons learned from randomized clinical trials in testicular cancer cases have been applied to the much fewer ovary tumors. VAC was the first efficient chemotherapy regimen to achieve about 50\% remission in advanced stages, and up to $85 \%$ in early stages in the treatment of NDOGCTs $[15,19]$. The inclusion of cisplatin in the systemic therapy of MOGCTs (PVB and BEP) has proven to yield a better chance of cure of up to $60-80 \%$, even with incompletely resected advanced-stage tumors [8,16,20-23]. The largest prospective study of BEP as adjuvant therapy was performed by GOG [23]. In the study, of 93 patients who had MOGCT and underwent three courses of BEP postoperatively, 89 patients have remained free of the disease $(89 / 93,96 \%)$. A multi-institutional trial reported that the BEP regimen showed equal efficacy and less toxicity than the PVB regimen in patients with testicular cancer [24], and therefore, the BEP regimen is regarded as the standard regimen for first-line chemotherapy of MOGCTs. In this study, the most common chemotherapeutic regimen selected was EP $(n=28)$ rather than $\operatorname{BEP}(\mathrm{n}=8)$. While a randomized study has found that three cycles of the BEP regimen are superior to the EP regimen in the case of testicular cancer (relapse-free survival rate, $84 \% v s .69 \%, P=0.03$ ) [25], because of the authors' terrible experiences in fatal pneumonitis associated with bleomycin, we selected the EP regimen for most of their patients with MOGCTs. As mentioned, the chemotherapy regimen was not influenced by the prognosis of MOGCTs, and the EP regimen was as highly effective as the BEP regimen in this study.

Given the prognosis and age of most of the patients, the important things to consider are the long-term sideeffects of chemotherapy. The most serious potential long-term forms of toxicity of chemotherapy are secondary malignancies, foremost of which is acute non-lymphoblastic leukemia. This is a well-known complication of relatively long-term alkylating agent therapy. In the study of Pedersen-Bjergaard et al., they described the mean cumulative risk of leukemic complications in 212 patients with germ cell tumors treated with BEP increased steadily from 15 months after start of etoposide and reached a mean of $4.7 \%$ at 5.7 years, and compared with the risk in the general population, the relative risk of overt leukemia was 336 [26]. The authors encountered a case of AML development in one patient 19 months after she started the etoposide-containing regimen $(1 / 36,2.8 \%)$, but the patient underwent allogenic bone marrow transplantation, and has no evidence of disease at present. Another important issue is the impact of chemotherapy on the reproductive function. According to a review of Gershenson, 27 of 40 patients who underwent fertility-sparing surgery maintained regular menses after their completion of chemotherapy, 33 had regular menstruation at the time of their follow-up, and of the 16 patients who had attempted to become pregnant since completing the chemotherapy, 11 delivered 22 healthy infants without major birth defects [27]. 
In a questionnaire-based study by Tangir et al., they reported that of 64 patients who underwent fertilitysparing surgery, 38 attempted conception and 29 became pregnant $(76 \%)$ with no congenital anomalies [28]. In this study, of the 14 patients who attempted to conceive after their treatment, $50 \%$ had successful pregnancies with no evidence of birth defects or other disabilities in any of their offspring.

This report was limited by its small number of cases due to the rarity of the disease, and the retrospective study design. This report has highlighted, however, the current state of clinicopathology, management, and prognosis of MOGCTs. In summary, this report showed that most MOGCTs have excellent prognosis with primary treatment, and good reproductive outcomes can be expected for them. Because the primary treatment failure is associated with the residual disease after the salvage surgery, knowledge of the presence or absence of this risk factor may be helpful in risk stratification and individualization of adjuvant therapy in MOGCTs. Further large-scale prospective studies to confirm these results are needed.

\section{Conclusions}

This study was undertaken to evaluate the clinicopathologic characteristics of MOGCTs and to determine the association of their prognostic factors to primary treatment failure in female patients. Residual tumor after the salvage surgery was found to be the only risk factor for primary treatment failure of MOGCTs, but most MOGCTs have excellent prognosis with primary treatment, and good reproductive outcomes can be expected for them. Further studies are required to determine the most effective management strategies in patients with these risk factors for primary treatment failure.

\section{Acknowledgements}

The authors thank Dr. Yong Gyu Park, Department of Biostatics, College of Medicine, the Catholic University of Korea, for statiscal advices.

\section{Author details}

'Department of Obstetrics and Gynecology, Yeouido St. Mary's Hospital, School of Medicine, the Catholic University, Yeouido-dong, Yeodeungpo-gu, Seoul, 150-713, Korea. ${ }^{2}$ Department of Obstetrics and Gynecology, Daejeon St. Mary's Hospital, School of Medicine, the Catholic University, 64, Daeheung-dong, Jung-gu, Daejeon, 301-723, Korea. ${ }^{3}$ Department of Obstetrics and Gynecology, Seoul St. Mary's Hospital, School of Medicine, the Catholic University, 505, Banpo-dong, Seocho-gu, Seoul, 137-040, Korea. ${ }^{4}$ Department of Obstetrics and Gynecology, St. Vincent Hospital, School of Medicine, the Catholic University, 93-6, Ji-dong, Paldal-gu. Geonggy-do, 442723 , Korea.

\section{Authors' contributions}

SYH, the corresponding author of this study, provided the major idea, planed and approved the written work. CWL contributed mainly in designing, literature review and writing the manuscript. Both STP and MJS collected the clinicopathologic data, and described all findings. EYK and SJL gave an important help for statistical analyses. KHL, KSR, and JSP gave advices about clinical variables to analyze and edited the discussion. All authors read and approved the manuscript.

\section{Competing interests}

The authors declare that they have no competing interests.

Received: 1 August 2011 Accepted: 11 October 2011

Published: 11 October 2011

\section{References}

1. Pectasides D, Pectasides E, Kassanos D: Germ cell tumors of ovary. Cancer Treat Rev 2008, 34:427-441.

2. Gershenson DM: Management of early ovarian cancer: germ cell and sexcord stromal tumors. Gynecol Oncol 1994, 55:62-72.

3. Gershenson DM: Update on malignant ovarian germ cell tumors. Cancer 1993, 71:1581-1590.

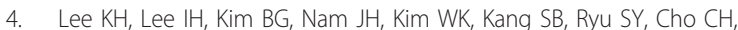
Choi HS, Kim KT: Clinicopathologic characteristics of malignant germ cell tumors in the ovaries of Korean women; A Korean Gynecologic Oncology Group Study. Int J Gynecol Cancer 2009, 19(Suppl 1):84-87.

5. Guillem V, Poveda A: Germ cell tumours of ovary. Clin Transl Oncol 2007, 9:237-243.

6. Kumar S, Shah JP, Christopher SB, Anthony NI, Michele LC, Rouba A, Marlone JM Jr, Morris RT: The prevalence and prognostic impact of lymph node metastasis in malignant germ cell tumors of the ovary. Gynecol Oncol 2008, 110(Suppl 2):125-132.

7. Serov SF, Scully RE, Sobin LJ: Histological typing of ovarian tumor. World Health Organization. International Histological Classification of Tumors Geneva, Switzerland: World Health Organization; 1973.

8. Lu KH, Gershenson DM: Update on the management of ovarian germ cell tumors. J Reprod Med 2005, 50:417-425.

9. Lai CH, Chang TC, Hsueh S, Wu TI, Chao A, Chou HH, Wang PN: Outcome and prognostic factors in ovarian germ cell malignancies. Gynecol Oncol 2005, 96(Suppl 3):784-791.

10. Murugaesu N, Schmid P, Dancey G, Agarwal R, Holden L, McNeish I, Savage PM, Newlands ES, Rustin G JS, Seckl MJ: Malignant ovarian germ cell tumors: identification of novel prognostic markers and long-term outcome after multimodality treatment. J Clin Oncol 2006, 24(Suppl 30):4862-4866.

11. Kawai M, Kano T, Furuhashi Y, Mizuno K, Nakashima N, Hattori SE, Kazeto S, lida S, Ohta M, Arii Y, Tomoda Y: Prognostic factors in yolk sac tumors of the ovary. Cancer 1991, 67(Suppl 1):184-192.

12. Nawa A, Obata N, Kikkawa F, Kawai M, Nagasaka T, Goto S, Nishimori K, Nakashima N: Prognostic factors of patients with yolk sac tumors of the ovary. Am J Obstet Gynecol 2001, 184(Suppl 6):1182-1188.

13. Ghaemmaghami F, Hasanzadeh M, Zarchi MKb, Fallahi A: Nondysgerminomatous ovarian tumors: Clinical characteristics, treatment, and outcome: A case-controlled study. Int J Surg 2008, 6(Suppl 5):382-386.

14. Mitchell PL, Al-Nasiri N, A'Hern R, Fisher C, Horwich A, Pinkerton CR, Shepherd JH, Gallagher C, Slevin M, Harper P, Osborne R, Mansi J, Oliver T, Gore ME: Treatment of nondysgerminomatous ovarian germ cell tumors: an analysis of 69 cases. Cancer 1999, 85(Suppl 10):2232-2244.

15. Slayton RE, Park RC, Silverberg SG, Shingleton H, Creasman WT, Blessing JA: Vincristine, dactinomycin and cyclophosphamide in the treatment of malignant germ cell tumors of the ovary. A Gynecologic Oncology Group Study (a final report). Cancer 1985, 56(Suppl 2):243-248.

16. Williams SD, Blessing JA, Moore DH, Homesley HD, Adcock L: Cisplatin, vinblastine and bleomycin in advanced and recurrent ovarian germ cell tumors. Ann Intern Med 1989, 111:22-27.

17. Kurman RJ, Norris HJ: Malignant germ cell tumors of the ovary. Hum Pathol 1977, 8(Suppl 5):551-564.

18. Tewari J, Cappuccini F, Disaia PJ, Berman ML, Manetta A, Kohler MF: Malignant germ cell tumors of the ovary. Obstet Gynecol 2000, 95(Suppl 1):128-133.

19. Gershenson DM, Copeland LJ, Kavanagh JJ, Cangir A, Del Junco G, Saul PB, Stringer CA, Freeman RS, Edwards CL, Wharton JT: Treatment of malignant non- dysgerminomatous germ cell tumors of the ovary with vincristine, dactinomycin, and cyclophosphamide. Cancer 1985, 56(Suppl 12):2756-61.

20. Gershenson DM, Kavanagh JJ, Copeland LJ, Del Junco G, Cangir A, Saul PB, Stringer CA, Edwards CL, Wharton JT: Treatment of malignant 
nondysgerminomatous germ cell tumors of the ovary with vinblastine, bleomycin, and cisplatin. Cancer 1986, 57(Suppl 9):1731-7.

21. Gershenson DM, Morris M, Cangir A, Kavanagh JJ, Stringer CA, Edwards CL, Silva EG, Wharton JT: Treatment of malignant germ cell tumors of the ovary with bleomycin, etoposide, and cisplatin. J Clin Oncol 1990, 8(Suppl 4):715-720.

22. Williams SD, Blessing JA, Hatch KD, Homesley HD: Chemotherapy of advanced dysgerminoma: trials of the Gynecologic Oncology Group. J Clin Oncol 1991, 9(Suppl 11):1950-1955.

23. Williams S, Blessing JA, Liao SY, Ball H, Hanjani P: Adjuvant therapy of ovarian germ cell tumors with cisplatin, etoposide, and bleomycin: a trial of the Gynecologic Oncology Group. J Clin Oncol 1994, 12(Suppl 4):701-706.

24. Williams SD, Stablein DM, Einhorn LH, Muggia FM, Weiss RB, Donohue JP, Paulson DF, Brunner KW, Jacobs EM, Spaulding JT: Immediate adjuvant chemotherapy versus observation with treatment at relapse in pathological stage II testicular cancer. N Engl J Med 1987, 317(Suppl 23):1433-1438.

25. Loehrer PJ Sr, Johnson D, Elson P, Einhorn LH, Trump D: Importance of bleomycin in favorable-prognosis disseminated germ cell tumors: an Eastern Cooperative Oncology Group trial. J Clin Oncol 1995, 13(Suppl 2):470-476.

26. Pedersen-Bjergaard J, Daugaard G, Hansen SW, Philip P, Larsen SO, Rorth M: Increased risk of myelodysplasia and leukaemia after etoposide, cisplatin, and bleomycin for germ cell tumours. Lancet 1991, 338(Suppl 8763):359-363

27. Gershenson DM: Menstrual and reproductive function after treatment with combination chemotherapy for malignant ovarian germ cell tumors. J Clin Oncol 1988, 6(Suppl 2):270-275.

28. Tangir J, Zelterman D, Ma W, Schwartz PE: Reproductive function after conservative surgery and chemotherapy for malignant germ cell tumors of the ovary. Obstet Gynecol 2003, 101(Suppl 2):251-257.

doi:10.1186/1477-7819-9-123

Cite this article as: Lee et al: Residual tumor after the salvage surgery is the major risk factors for primary treatment failure in malignant ovarian germ cell tumors: A retrospective study of single institution. World Journal of Surgical Oncology 2011 9:123.

\section{Submit your next manuscript to BioMed Central and take full advantage of:}

- Convenient online submission

- Thorough peer review

- No space constraints or color figure charges

- Immediate publication on acceptance

- Inclusion in PubMed, CAS, Scopus and Google Scholar

- Research which is freely available for redistribution

Submit your manuscript at www.biomedcentral.com/submit
Biomed Central 